\title{
SECULARIZAÇÃO OU RESSACRALIZAÇÃO? $O$ debate sociológico contemporâneo sobre a teoria da secularização
}

\section{José de Jesús Legorreta Zepeda}

\author{
Tradução de Paula Carpenter
}

\section{Introdução}

A religião sempre foi um fenômeno sociocultural inevitável quando se tenta analisar e compreender qualquer sociedade. Já os chamados clássicos da sociologia (Comte, Durkheim, Marx, Weber e Parsons, entre outros) manifestaram de diversas perspectivas a importância desta questão para compreender a origem, a natureza e o sentido das sociedades modernas. A maioria desses autores, concentrando sua atenção particularmente no caso europeu, coincidiram com que o advento da modernidade traria consigo o deslocamento do centro da vida da sociedade para a periferia, assim como transferiria algumas funções essenciais que a religião desempenhava nas sociedades tradicionais (legitimação, coesão social, sentido etc.) a outras

Artigo recebido em janeiro/2009

Aprovado em novembro/2009 instituições e referências simbólicas. Alguns autores inclusive chegaram a pensar que com a modernização da sociedade a religião poderia decrescer ou até desaparecer. A este conjunto de mudanças pelo qual a religião perde sua relevância social, ideológica e institucional é o que genericamente chamamos secularização. ${ }^{1}$

A partir do último terço do século XX, começou a tomar força a opinião de que o projeto da modernidade estava em crise, e com ele alguns dos principais projetos e promessas. Entre muitos outros sintomas de tal situação, a religião seria, sem dúvida, um elemento referencial, já que em vez de desaparecer, como haviam sugerido diversas vozes desde o século XIX, não somente resistia nas suas diversas formas, como também começava a se assistir com assombro um intenso e extenso surgimento de novos movimentos religiosos. O problema então já não seria como explicar o declínio da religião (questão para a qual tentava dar respostas a teoria 
da secularização), mas explicar sua grande exuberância na crise da modernidade globalizada. Portanto, a utilidade das teorias da secularização seria posta à prova em virtude de sua incapacidade de explicar a nova situação da religião nas sociedades contemporâneas.

No entanto, uma análise superficial da bibliografia sociológica especializada (sociologia da religião) não endossa abertamente a conclusão acima referida, mas o que mostra é uma intensa discussão entre os especialistas, cujos argumentos revelam muito da base ideológica e mecanicista que subjaz à concepção amplamente difundida de "secularização" como "sem religião". E mais, grande parte dos sociólogos que abordam esse problema chegam inclusive a sustentar que a noção de secularização possui grande potencial explicativo da religiáo mesmo em condiçōes de globalização e pós-modernidade. Um breve relato deste debate sociológico é o que apresentaremos a seguir, a fim de refletir, a partir de uma perspectiva ideológica, a utilidade ou não do conceito de secularização para explicar a atual efervescência religiosa.

\section{A teoria da secularização em debate}

O debate em torno da secularização realiza-se em estreita relação com o debate em torno da modernidade. Além da variedade de suas realizaçôes históricas e interpretaçōes, na discussão sociológica pode-se identificar uma série de características do que tem se denominado modernidade: trata-se de um processo sócio-histórico complexo e multidimensional - original da Europa Central -, caracterizado fundamentalmente por uma visão de mundo descentrada, profana e pluralista, por uma reflexão que ao incorporar-se de forma sistemática e permanente na vida social, desestabiliza a experiência, as instituições e os conhecimentos, e conseqüentemente gera uma realidade profundamente dinâmica, contraditória, ambígua e precária. Também podem-se mencionar, como características típicas da modernidade, a primazia da razão instrumental, o individualismo, a compreensão otimista da história como progresso, bem como a diferenciação institucional. ${ }^{2}$ Como podemos perceber, a modernidade, de uma ou outra forma, implica uma alteração do papel central desempenhado pela a religião em $s o-$ ciedades tradicionais, como elemento legitimador $\mathrm{e}$ integrador, dando sentido e articulando as diferentes esferas sociais. Este processo, usualmente conhecido como "processo de secularização", foi lido por diversos teóricos (Comte, Spencer, Marx) como uma dinâmica de emancipação cujo fim levaria a uma sociedade "sem religião".

Esta hipótese utópica própria dos primórdios da sociologia parecia confirmar-se historicamente em três fatos mais ou menos contundentes: 1) o paulatino deslocamento da religião-institucional do centro para a margem da incipiente sociedade moderna européia, 2) a perda do monopólio de visão de mundo da religião e seu rebaixamento para a mentalidade científica e liberal, 3) o paulatino, mas constante declínio da relevância social dos signos, símbolos e das instituiçōes religiosas. No entanto, Durkheim e Weber, para citar somente alguns, já viam que o postulado do "desaparecimento inevitável da religião" tornava-se problemático. Durkheim, por exemplo, afirma que "há algo eterno na religião que está destinado a sobreviver a todos os símbolos particulares com que sucessivamente se tem revestido o pensamento religioso" (Durkheim, 1982, p. 387), com o qual deixava aberta a possibilidade de afirmar que não obstante as mudanças nas formas, a religião permaneceria. Weber, por outro lado, referindo-se ao "desencantamento do mundo" assinalava que este processo estava longe de conduzir de forma linear e progressiva a uma visão de mundo determinada plenamente pelo cálculo e pela previsão, pois também advertia como a ciência experimentava em muitos de seus contemporâneos uma espécie de "reencantamento" ao conceber-se como um reino ultraterreno de abstraçōes artificiais, sem pressupostos prévios e com pretensōes quase religiosas de que seus resultados fossem "dignos de ser conhecidos" (Weber, 2000, pp. 200-208). Para ambos os autores, mesmo que a religião fosse perdendo sua influência social, também ficava mais ou menos claro que não estava necessariamente condenada a desaparecer, mas sim a transformar-se, desfazendo-se de algumas fórmulas mágicas e adotando outras novas. As intuiçōes dos denominados mestres da suspeita (Nietzsche, Marx e Freud) que 
identificaram com argumentos sólidos na religião um fenômeno alienante, levariam muitos a pensar apressadamente que a emancipação da religião tornaria inevitável seu fim, conceito que longe de ser um puro postulado teórico se tornou ainda um programa político-ideológico.

Essas discussóes revelaram duas abordagens ou teses dominantes sobre a secularização válidas até hoje: a primeira poderia ser chamada de "tese dura ou forte da secularização" e seria concebida como um processo lento e inexorável a caminho do fim da religião; a segunda, ou seja, a "tese suave da secularização" afirmará que se trata de um processo pelo qual a religião sofre severas alteraçōes na modernidade, mas persiste disseminada pelos interstícios da cultura, disfarçada ou oculta na economia como "espírito do capitalismo", na política como "religião civil", ou como formas socioculturais pouco relevantes. Apesar dessas distinções, as tensōes e as lutas que provocaram os processos de secularização, especialmente em sociedades enraizadas em monopólios religiosos, transformaram a "tese dura" em um programa político a ser atingido de forma deliberada, em muitos casos a qualquer custo, como na França, no México e na ex-União Soviética. Estes e outros elementos, nos quais não nos aprofundaremos neste momento, levaram a identificar a secularização como uma teoria para explicar o inevitável desaparecimento da religião nas sociedades modernas.

Rumo ao último terço do século XX, Peter Berger e Thomas Luckmann deram um novo impulso à reflexão sociológica sobre a secularização ao constatar, desde diversos ângulos, os limites e as insuficiências da chamada "tese dura". Berger, embora constatasse que na modernidade o processo de racionalização, institucionalizado na economia, a técnica e a burocracia haviam deslocado a religião do centro da sociedade para o âmbito privado, também advertia que esse fato possibilitava um pluralismo religioso, desmonopolizando as tradiçóes religiosas hegemônicas, colocando-as em concorrência umas com as outras, mas não eliminando-as (Berger, 1981, especialmente a Segunda Parte). Nesse mesmo sentido, Luckmann deteve-se na dimensão individual ou privada da religião na modernidade, destacando sua persistência como uma constan- te antropológica, mas também sua capacidade de mudança (Luckmann, 1973). De tal forma que, diferentemente daquelas teorias teleológicas que previam o fim da religião, Luckmann provou, a partir de uma perspectiva histórico-antropológica, como a religião, em vez de se destruir, transformava-se influenciada pela estrutura simbólica e social na qual tinha lugar. Esta constatação o levou a tratar de diversas "formas sociais de religião", sendo a religião individual ou invisível - como ele preferia chamar a mais adequada à sociedade secular (Luckmann, 1989, pp. 87-108). A intuição de Luckmann sobre a persistência da religião como uma constante antropológica foi confirmada na maioria das sociedades ocidentais no último terço do século XX, onde se testemunharia a persistência religiosa não somente nas suas formas tradicionais, mas também em novos movimentos religiosos. Ali, a teoria da secularização entendida como a-religiosidade ficava desacreditada nos fatos, além de mostrar-se teoricamente incapaz de explicar essa espécie de "reencantamento" do mundo.

\section{Críticas à teoria da secularização}

Geralmente as críticas à teoria da secularização foram dirigidas justamente ao que chamamos de "tese dura". Elas se configuram em duas frentes: no primeiro caso desde a mesma realidade histórica, em que o caso norte-americano é paradigmático, pois, não obstante ser em muitos sentidos o protótipo da sociedade moderna, podemos observar uma religiosidade permanente e exuberante, o que mostra que modernidade e religião não são incompatíveis. A outra frente é de cunho mais teórico: Wilson, por exemplo, afirma em diversos trabalhos que as abordagens que procuram reduzir ou eliminar a religião (com suas instituições, crenças e práticas) da vida social moderna fazem referência mais a uma ideologia - o secularismo - do que a uma teoria social (1998, p. 46). Nesse mesmo sentido, o peculiar conceito evolutivo e teleológico da secularização tem sido criticado por seus pressupostos históricos: se com o avanço da modernidade a religião tende a decrescer, isto faria supor que em algum momento do passado existiu algo como "a idade da fé". Porém, uma análise histórica mais detalhada mostrará 
quão longe estiveram outras sociedades de ser algo mais que religiosas (Stark, 1999, pp. 255-260). Outra objeção diz respeito a seu inegável caráter etnocêntrico, que tende a identificar a rota do fenômeno religioso ocorrido na Europa ocidental como caminho paradigmático pelo qual deverão transitar as outras sociedades, omitindo experiências históricas em que a religião teve grande vitalidade, como no caso dos Estados Unidos, da América Latina e da Ásia (Martin, 1991, p. 466). Somado a isso, temos a objeção, já mencionada, da visão evolutiva e linear que supõe tal idéia de secularização, na qual perde-se de vista que esse processo é claramente uma variável dependente de cada universo sociocultural, dos interesses de grupos e indivíduos e do próprio caminho traçado pelas vicissitudes dos processos de modernização. Nesse contexto, se não há propriamente uma modernidade, mas muitas em permanente disputa (Beriain, 2005), também não se pode falar de um destino único e inescapável da secularização; portanto, há tantas e variáveis secularizações como modernidades existem (Casanova, 2007, pp. 5-8). Pode-se questionar até mesmo a irreversibilidade que pressupóe o conceito duro de secularização, pois se é certo - como afirma Karel Dobbelaere - que as possibilidades de "deslaicização" na economia ou na política são muito raras, existem âmbitos, como o familiar ou da educação, em que o conflito entre quem advoga por enfoques racionais e os que lutam por perspectivas ético-religiosas não permite descartar a priori uma possível "deslaicização" dessas esferas (Dobbilaere, 1994, p. 60). Por fim, o conceito de secularização unilinear e progressivo padece de uma visão similar a respeito de mudança e diversidade social que ignora haver na dinâmica de um e outro processo hibridações, fragmentações e verdadeiras torções, de modo que a modernidade em sua fase atual, por exemplo, não é só, nem principalmente, o resultado do suposto "progresso" perseguido pelo projeto esboçado no Iluminismo, mas também e, talvez, a conseqüência da mistura de ações desejadas e não desejadas, de seus efeitos colaterais, advertidos, imprevistos e até desconhecidos, dando lugar a uma nova etapa da modernidade, cuja denominação variará de acordo com o ângulo e o enfoque que se privilegie: sociedade do risco (Beck), modernidade radical (Gid- dens), modernidade tardia (Habermas) ou pós-modernidade (Vattimo, Lyotard etc.). ${ }^{3}$ Em qualquer caso, uma teoria complexa de mudança social deve se correlacionar a uma teoria complexa da secularização. Ignorar isto leva a afirmações igualmente simplistas quando se faz referência ao surgimento de novos movimentos religiosos ("ressacralização", "retorno do religioso" ou "vingança de Deus"), na forma de um retorno igualmente linear e mecânico à situação anterior à modernidade que. se não era exatamente uma “idade da fé", tinha a religião desempenhando um papel central nos níveis institucional, sociocultural e subjetivo.

Se por secularização entende-se o processo pelo qual a religião tende a desaparecer inevitavelmente nas sociedades modernas, vários fatos históricos e a discussão sociológica mostraram que tal afirmação é insustentável. Uma das atitudes mais comuns entre alguns estudiosos do assunto diante do descrédito do conceito de secularização consiste em rejeitar essa noção por sua incapacidade explicativa e preditiva do fenômeno religioso nas sociedades contemporâneas. Autores célebres do renascimento da sociologia da religião nas décadas de 1960 e 1970, como Peter Berger, quem certamente colocou novamente na arena da sociologia o tema da secularização sob o ponto de vista histórico e sistemático (Berger, 1981), a partir dos anos de 1990 optaram, para explicar as mudanças religiosas nas sociedades atuais, por explorar o "pluralismo" e seus efeitos relativizantes e sincréticos nas crenças (Berger, 1993, pp. 39-64). Diante dessa situação, o título do artigo de Stark refere-se ao epitáfio com que se poderia sepultar a noção "Secularização: R.I.P.”. Seria então uma noção puramente ideológica? As mudanças e os fenômenos sociais a que se referiam os sociólogos da religião nunca existiram? E caso tenham existido hoje não perduram mais? Nunca realmente foi composta uma teoria sistemática a esse respeito? Tais questões têm ocupado os sociólogos da religião nas três últimas décadas, cujas conclusões apresentaremos a seguir.

\section{Secularização: um paradigma multidimensional}

Entre os sociólogos da religião pode-se identificar um grupo que, apesar de mostrarem-se críticos 
ao uso ideológico, preditivo e mecânico da teoria da secularização, descartam a idéia de rejeitá-la. Um dos mais importantes estudiosos que segue esta linha é Karel Dobbelaere, sociólogo da religião da Universidade Católica de Lovaina. Em seu famoso relatório sobre as tendências da secularização, faz uma revisão a respeito do tema (desde os clássicos da sociologia até a segunda metade do século XX), na qual constata que a teoria da secularização é primeiramente um "conceito de sensibilização" que oferece um sentido geral de referência e orientação, abordando casos empíricos (Dobbelaere, 1994, pp. 7-8). Porém, ele também adverte que caso se queira fazer uso científico do conceito e não utilizá-lo simplesmente como um "estereótipo vago" é preciso diferenciar três dimensōes: laicizacão, mudança religiosa e participação em igrejas. A primeira mediria as inter-relaçôes entre as instituiçōes religiosas $\mathrm{e}$ as instituiçôes sociais, incluindo aí três processos complementares: profanação, diferenciação e transposição. $\mathrm{Na}$ segunda caberiam as mudanças que ocorrem no interior do mundo religioso em matéria de crenças, moral e ritos, assim como o rebaixamento e o surgimento de comunidades religiosas. Cabe salientar que esse nível se mantém também no plano institucional, só que restrito no interior das próprias instituiçóes religiosas. A terceira dimensão trataria das mudanças que ocorrem na relação indivíduo-instituição religiosa, referindo-se ao grau de integração normativa dos indivíduos com respeito às corporações religiosas (Idem, pp. 2-8). Com base nessas diferenciações, o autor imprime nas teorias sociológicas sobre a secularização um status de verdadeiras "teorias sociais" e não simples recursos ideológicos. Aprofundando-se nesta questão, Dobbelaere apresenta alguns anos depois em um breve trabalho, mas não menos estimulante para a reflexão sociológica, a necessidade de levar em conta os paradigmas sociais que subjazem às teorias sobre a secularização (refere-se principalmente a Luckmann, Berger, Wilson e Luhmann), com a finalidade de diferenciar os paradigmas e os níveis subseqüentes de análise (Dobbelaere, 1985, pp. 377-387).

Próximos a esta interpretação, situam-se Peter Beyer, professor do Departamento de Estudos Clássicos e Religiosos da Universidade de Otawa, e José Casanova, professor de Sociologia na New School University de New York. O primeiro assume praticamente todas as diferenciaçôes de Dobbelaere com a novidade de considerá-las válidas no contexto de globalização (Beyer, 1999, pp. 289-301). O segundo, por outro lado, refere-se à secularização como um paradigma no qual distingue três diferentes propostas: a) secularização como diferenciação estrutural e funcional (emancipaçāo) das esferas seculares com respeito às instituiçôes $e$ às normas religiosas, identificando-a como uma tendência generalizada no mundo moderno; b) secularização como declínio nas crenças e práticas religiosas, que, de forma diferente da anterior, não é uma tendência estrutural moderna, mesmo sendo uma tendência histórica dominante em muitas sociedades ocidentais, principalmente européias; e c) secularização como marginalização da religiāo à esfera privada, uma tese que também não é tendência estrutural da modernidade, mas uma opção histórica prescrita ideologicamente na estrutura do pensamento moderno ocidental (Casanova, 1995, pp. 395-410). Sua contribuição, portanto, está em identificar como apenas a diferenciação institucional das esferas seculares com respeito às instituições $\mathrm{e}$ às normas religiosas (o que Dobbelaere chamaria de laicizacão) pode ser considerado um elemento secularizador inerente à modernidade, diferentemente das outras duas dimensōes. Nessa mesma perspectiva encontra-se um grande grupo de autores (Luckmann, Voyé, Beyer, Wilson, Tschannen, Luhmann, Rubio e Mardones, entre outros) que ainda consideram valiosa a tese da secularização no que diz respeito à dimensão institucional ou social, que é um instrumento útil não somente na modernidade como também nas peculiares condiçóes da modernidade tardia e globalizada do mundo contemporâneo.

Podemos afirmar que as reflexões sociológicas sobre a secularização constituem uma teoria sistemática? Oliver Tschannen afirma que a soma dos diversos elementos do corpus conceptual sobre a secularização não dá lugar a uma teoria sistemática e coerente, mas não concorda com Jeffrey Hadden e outros sociólogos que "a teoria da secularização é mais uma miscelânea de idéias desarticuladas do que uma teoria sistemática" (Tschannen, 1991, 
p. 395). Ele, na verdade, sustenta que o corpus conceptual sobre a secularização constitui um autêntico "paradigma" no sentido kuhniano da expressão, ou seja, forma um quadro coerente de conceitos compartilhados em torno de três elementos centrais: diferenciação, racionalização e mundanização. Além disso, segundo ele, esse paradigma abriu espaço neste contexto para a comunidade científica que faz "ciência normal - sociológica" a partir de suas próprias nuanças, acentos e vertentes teóricas. Essa comunidade estaria basicamente formada por autores como Luckmann, Berger, Wilson, Martin, Fenn, Parsons, Dobbelaere e Bellah, que particularmente não representam plenamente o paradigma, mas compartilham basicamente seus elementos centrais. ${ }^{4}$ A proposta de Tschannen, que em outro texto ele vê confirmada ao comparar o caso europeu e o latino-americano (2004, pp. 353-366), parece-nos a postura mais aceitável, pois sem se esquivar das críticas mais agudas à secularização, assim como Dobbelaere e outros, supera abordagens reducionistas e teleológicas, ao mesmo tempo em que consegue identificar e valorizar um quadro conceitual sociológico útil para dar conta das dinâmicas e das tendências do fenômeno religioso nas sociedades contemporâneas, tanto na persistência de suas antigas expressões, como em suas novas formas.

\section{Secularização, pós-modernidade e globalização}

Outro tipo de crítica que se faz às abordagens sobre secularização diz respeito ao fato de que se trata de uma teoria ad hoc para um contexto de modernidade em que o objetivo era explicar como e por que diminuía a influência religiosa na vida social. Em um contexto pós-moderno, o problema é oposto, ou seja, procuram-se entender e compreender as causas e as tendências desta espécie de "ressurgimento religioso", "ressacralização" ou no sentido weberiano do "reencantamento". 5 Refletirmos sobre essas abordagens implica em definir, mesmo que brevemente, o que se entende por pósmodernidade e a nova configuração que a religião tem experimentado nesse lugar.
Pós-modernidade e religiāo: secularização ou ressacralização?

Desde o último terço do século XX tornou-se lugar comum falar da "crise da modernidade". Com essa expressão procura-se sinalizar o mal-estar generalizado que experimenta o homem comum (por exemplo, na desorientação e nas incertezas perante os valores) em relação ao sistema econômico e ao espaço político. Estes se tornaram incapazes de solucionar as enormes diferenças entre o chamado primeiro mundo e o restante das nações, entre a grande massa dos excluídos e as pequenas elites que monopolizam o poder político e econômico. Isso tem levado a questionar os "grandes discursos" ou "metarelatos" sobre os quais se ergueu a modernidade (progresso, primazia da razão, universalismo etc.), assim como seu otimismo emancipatório herdado do Iluminismo. Alguns autores não hesitam em situar a crise estrutural e de valores na cultura, isto é, no âmbito das formas simbólicas em que a sociedade organiza seu acervo de padrōes de interpretação, valores, mitos e crenças. ${ }^{6}$ Para os críticos sociais (sendo Habermas seu maior representante, incluindo também Claus Offe, Alain Touraine e Anthony Giddens), as contradições e as incertezas inerentes a esta nova situação, mais do que apontar para o fim da modernidade, como assinalaram os pós-modernos, indicam que assistimos à radicalização daquelas tendências e tensões ambivalentes que já estavam presentes. Dessa perspectiva, a chamada crise da modernidade não seria um réquiem ou o limiar de uma nova época (pós-modernidade), mas sim a expressão de outra fase da modernidade, gerada por uma teia de conseqüências desejadas, não desejadas e desconhecidas, assim como pelos triunfos e fracassos da modernidade iluminista ou industrial. ${ }^{7}$ Mas, então, como referir-se a essa nova realidade? Como estabelecer suas conexões, estruturação ou desestruturação em relação à sua fase anterior? A este respeito, vários analistas sociais, a partir de diferentes referencias teóricos, têm cunhado expressões sem justapor a continuidade ou a descontinuidade entre essas duas etapas da modernidade como, por exemplo, "modernidade radicalizada" (Giddens), "modernidade reflexiva" (Luhmann), "desmodernização" (Touraine) e "modernidade liberal ampliada" (Wagner). 
Este novo contexto tem modificado o campo de estudos da religião. Talvez dois dos sintomas tenha sido a persistência das tradiçôes institucionais religiosas (apesar de sua tendência decrescente) e, sobretudo, o surgimento de novos movimentos religiosos. Em relação ao primeiro, Lilian Voyé sustenta que, perante o desencantamento dos "metarelatos" científicos, éticos, nacionalistas e de identidade específica do novo contexto, as tradiçôes religiosas são requeridas com freqüência por conta de sua capacidade de outorgar sentido, identidade e um horizonte de valores para os indivíduos. Ela não supõe o retorno à situação religiosa pré-moderna - de hegemonia da grandes instituições religiosas -, ao contrário, afirma que elas se encontram limitadas, sem foco no social, relativizadas por um contexto pluralista e sujeitas à contestação interna e externa. O processo de secularização em sua dimensão de diferenciação institucional não permanece invalidado (Voyé, 1999, pp. 275-288). A proliferação de novos movimentos religiosos, por seu turno, é um dos aspectos que mais tem chamado a atenção atualmente. Não poucos estudiosos do tema concluíram precipitadamente que a teoria da secularização se revelou falsa e, desde então, têm decretado seu fim. Mas será que, realmente, estamos assistindo a um ressurgimento religioso? Estaria ocorrendo um "reencantamento" do mundo? Respostas nesse sentido exigem um aprofundamento da análise, identificando qual é a religião que ressurge e como isto se dá nessa fase da modernidade. É necessário refletir se tal situação abala a teoria da secularização a ponto de se precisar recorrer a outros tipos de propostas explicativas.

A maioria dos estudos a respeito do ressurgimento religioso tem mostrado que, no caso ocidental, não são as principais instituições religiosas que têm ou se "revitalizado"; pelo contrário, salvo algumas exceções, quando o espírito nacionalista ou reivindicatório se encontra e estreitamente ligado a uma determinada igreja, são as igrejas católica, luterana, anglicana etc. que diminuíram seu campo de alcance e influência, tendência que se manifesta em alguns aspectos da religiosidade mais do que em outros, mas que ocorre igualmente em todas essas igrejas, sobretudo em áreas urbanas (Bastian, 1997; Legorreta, 2003). ${ }^{8}$ Ao mesmo tempo observa-se um crescimento explosivo na diversidade religiosa, desde "fundamentalismos" (testemunhas de Jeová, mórmons, igrejas eletrônicas, fundamentalismos católicos etc.) passando por religiōes de matriz oriental (hare krishna, meditação transcendental e novas formas de budismo) até o sincretismo religioso esotérico-holista da New Age (Mardones, 1994, pp. 113128). Todas essas expressões religiosas compartilham de uma ou outra forma o "espírito" da "modernidade radicalizada": desconfiança ante a racionalidade contemporânea, pretensão de ruptura ante as práticas e as formas religiosas institucionais herdadas e de forte carga "emocional" e individual, exceto alguns fundamentalismos (Hervieu-Leger, 1987, pp. 221-222). Em especial, os movimentos religiosos baseados em intensa carga emocional, os que mais abundam hoje, são altamente adaptáveis às condições do novo contexto: carecem de pontos fixos de referência, tradição ou autoridade; apostam mais na experimentação do que na crença, são sincréticos por natureza e não se estruturam mais em torno do eixo "transcendênciaimanência", em torno de um eixo horizontal: "sentido/sem sentido", "vida/morte", "saúde/doença" etc. (Rubio, 1998, p. 20).

Quais seriam as conseqüências desse inesperado revival religioso no interior do processo de secularização? Tal "ressurgimento" religioso não só mantêm, como também reafirma, em nome da experiência pessoal e subjetiva, uma rejeição ao controle institucional de crenças e práticas (com exceção de alguns grupos "integristas"), de modo que essa vitalidade religiosa está longe de ser uma mera regressão à tradição religiosa pré-moderna, que tinha monopólio institucional e ocupava o centro da vida social. Em vez disso, o que observamos é uma radicalização da "diferenciação" vislumbrada por Weber dentro das próprias crenças e das novas formas religiosas. ${ }^{9}$ Essa situação peculiar é o que possibilita compreender a constante disseminação da religião nos interstícios das esferas públicas e privadas, assim como o surgimento cada vez maior de uma religiosidade de bricolage, de uma "religião à la carte", desenhada de acordo com preferências individuais, mais do que seguindo a lógica e a coerência de um sistema doutrinal. Portanto, a vitalidade dessas formas emocionais de religião não nega a teoria da secularização, já que agora, mais do que antes, a proliferação de grupos religiosos, a competição entre eles e a precariedade de 
suas adesões e crenças debilitam qualquer pretensão de tornar a instituição religiosa um fator de coesão social (Idem, pp. 13-15). Em suma, a secularização instalou o "reino do fragmento" (pluralismo) entre as próprias instituições religiosas, as quais vivem um processo inevitável de relativização. Os indivíduos, por sua vez, vêem-se condenados a escolher e a flexibilizar as crenças.

Essa condição inédita da religião na modernidade tardia é o que Martelli chama de "dessecularização", em vez de ressacralização. Para ele, essa nova forma social de religião não obedece a um processo evolutivo linear, mas à lógica em que a pós-modernidade funciona; isto é, mediante um triplo e paradoxal movimento: manutenção, recuperação e distorção (Martelli, 1999, pp. 160-161). Manutenção significa a permanência de organizaçôes, identidades e valores religiosos herdados; no segundo movimento ocorre uma recuperação não tradicional (Giddens) de símbolos, tradiçôes e crenças religiosas, o que não implica em um simples retorno à fusão de instituiçôes ou à restauração do cesaropapismo. Quanto à distorção, o autor deseja mostrar que os resultados podem ser imprevisíveis, apresentando até mesmo um caráter destrutivo, como o suicídio coletivo ocorrido na "Porta do Céu” , em 1997, ou outros casos semelhantes. O autor conclui, então, que a "dessecularização é o retorno não tradicional à tradição ético-religiosa, com efeitos ambivalentes e de distorçôes", o que torna obsoletas tanto uma teoria linear da secularização, como sua contrapartida, a simples ressacralização (Idem, pp. 164-165). $\mathrm{Na}$ verdade, o processo de dessecularização coexiste com o processo de secularização, isto é, mantémse a emancipação de diversas instituições da tutela religiosa, ao mesmo tempo em que as crenças e as práticas herdadas coexistem e interpenetram-se com novas crenças e movimentos religiosos, criando uma situação inédita, pois nem se trata de um simples retorno religioso do passado, tampouco de uma dissolução da secularização.

\section{Da "sociedade secularizada" a} "sociedade pós-secular"

Em primeiro lugar, é inegável a persistência e a efervescência religiosa paralelamente a um descré- dito da razão instrumental (creditado em grande parte pela crise da modernidade e a crítica pósmoderna). Em segundo lugar, esse novo contexto conduz à revalorização do plano simbólico e à necessidade de se dar sentido à vida, elementos que estão intrinsecamente articulados em todas as tradiçôes religiosas. Isso possibilita a existência da tolerância religiosa, como também sua revalorização na esfera pública. Assim, pode-se falar em "religiôes públicas", não no sentido pré-moderno de religiōes que atuam de maneira central no espaço público (por exemplo, “igrejas oficiais"), nem no sentido de religiōes competindo com outras como se fossem partidos políticos, no sentido de que operam publicamente no espaço da "sociedade civil". José Casanova define a "religião pública" como aquela que,

[...] mesmo aceitando a desoficialização estatal e a neutralidade com respeito à disputa política, reclamam pelo direito de intervir, dialógica ou polemicamente na esfera pública da sociedade civil. O resultado dessa reformulação é uma concepção da religião pública compatível com as liberdades do liberalismo e com a moderna diferenciação estrutural e cultural (Casanova, 1995 , p. 404).

Este tipo de religião parece estar cada vez mais presente nas sociedades contemporâneas, quando, por exemplo, posiciona-se pela defesa de liberdades e direitos em regimes autoritários, ou intervém em debates públicos, insistindo em consideraçôes éticas. Trata-se, em suma, de uma nova presença pública da religião, não "reativa" nem fundamentalista, muito menos governista, , mas sobretudo dialógica.

Jürgen Habermas recentemente mostrou interesse em afrontar essa nova situação da religião na esfera pública das sociedades modernas. Ele chama a persistência indefinida das comunidades religiosas em um ambiente secularizador de sociedade "póssecular" (Habernas, 2001). Trata-se de uma sociedade que tem superado a "fé cientificista" de uma pura e dura compreensão objetiva do ser humano (que nem é ciência, mas filosofia ruim), concedendo às convicçôes religiosas, com seus fundamentos morais, ser uma voz necessária entre outras no in- 
terior do espaço público. Habermas considera as tradiçôes éticas ou religiosas imprescindíveis para a sustentação do Estado liberal (Habermas, 2004), o que não quer dizer que o Estado não possa cumprir de maneira positiva seu papel em uma ordem constitucional, mas ele não consegue fazer o mesmo em relação ao aspecto motivacional. A motivação que permite aos cidadãos a solidariedade e o respeito à ordem constituída obedece a insumos pré-políticos, cujas fontes são "projetos éticos de vida", ou seja, ideais de existência, cujo alimento continua sendo, apesar de tudo, religioso. Com base nisso, Habermas entende a sociedade pós-secular não somente como o entorno secular onde persistem as comunidades religiosas e onde elas são reconhecidas por sua contribuição funcional por "motivos e atitudes que fazem bem a todos", mas também como "a modernização da consciência pública”, na qual, apesar de suas diferenças, se encontram e se interpenetram as mentalidades religiosas e mundanas, no sentido de opinar em temas controversos no espaço público (Idem).

Esse novo tipo de presença e revalorização do plano religioso pressupõe os efeitos dos processos da secularização e até mesmo sua radicalização, mas em um contexto não impregnado do mito cientificista e evolucionista/progressivo próprio do Iluminismo. Talvez os acontecimentos do memorável "11 de Setembro" possam ilustrar o que queremos dizer. Naquele momento, no mais íntimo da sociedade secular uma "fibra" religiosa surgiu, de modo que, embora as razões político/religiosas do atentado eram de algum modo evidentes, as reaçóes também assumiram contornos religiosos, manifestando-se em uma série de fatos, como a indignação e a solidariedade diante do atentado, o sentimento da "sacralidade" de um estilo de vida manchado pelos suicidas, os discursos de vingança e reparo etc. Ali, não prevaleceu uma análise científico-técnico dos acontecimentos, mas ninguém se sentiu lesado por isso, nem lamentou que estivesse assistindo ao desmoronamento do caráter secular da modernidade. Pelo contrário, espontaneamente as pessoas buscavam explicações étnicas, religiosas e racionais para dar conta do que aconteceu.

Sem dúvida, esta nova "arena" de encontro entre a religião e a razão abre-se para um grande debate permeado por pontos de vista diversos e com resultados inesperados. No campo teológico, por exemplo, já há alguns anos surgem novas abordagens interdisciplinares entre ciência, sociedade e religião dentro de um contexto pós-secular. ${ }^{10}$

\section{A religiāo na globalização}

Uma visão geral sobre a situação da religião nas sociedades contemporâneas estaria incompleta se não se pautasse pelas dinâmicas da globalização. Nos últimos cinqüenta anos a modernidade radicalizada tem assistido a um processo acelerado e intenso de intercâmbio entre indivíduos, culturas, capitais, símbolos e instituições, o que vem desterritorializando identidades, culturas, relaçôes sociais e econômicas, entre outras conseqüências. Esta "interconectividade complexa", nas palavras de Giddens, é o que se conhece como "globalização” (Giddens, 1990, pp. 67ss). Tal fenômeno é conseqüência da modernidade radicalizada, que proporcionou as condiçôes socioinstitucionais (capitalismo, industrialização, comunicação de massa, urbanismo, Estado nacional etc.) e o imaginário cultural (que inclui diferentes formas de racionalidade, cosmologia, valores, crenças, conceitualização do tempo e espaço) que tornaram a globalização possível (Tomlinson, 2001, Capítulo 2).

Nesse contexto, a religião comporta-se tanto como uma força negativa da globalização, servindo, para certos grupos, de referência para uma identidade histórica ou étnica e fortalecendo, assim, a cultura local, quanto como uma força pró-ativa, que assume um caráter eminentemente expansivo e homogeneizador, como ocorre com o catolicismo romano e alguns movimentos islâmicos na modernidade globalizada (Beyer, 1994). Evidentemente, essas dinâmicas religiosas não são completamente novas, o que difere é a intensidade, a complexidade e a escala global que agora alcançam. Talvez um dos casos mais ilustrativo seja o das identidades. A identidade é uma constante antropológica eminentemente relacional e dinâmica, em que a religião sempre desempenhou um papel fundamental. Em um contexto de globalização, onde ocorre uma intensa e maciça interação entre grupos e indivíduos, não é fácil que as identidades "nativas" permane- 
çam inalteradas, apesar das freqüentes tentativas de fechar-se. Quando isto ocorre, em um contexto onde sujeitos de uma determinada identidade são ou foram marginalizados ou oprimidos, a religião costuma ser o baluarte do entrincheiramento sociocultural e, nesse sentido, contrassistêmico. Em outros casos acontece mais ou menos o contrário: a religião, ao se desprivatizar e se desterritoratizar (como têm acontecido com certas formas de catolicismo e islamismo), adquire uma dinâmica funcional em relação à globalização, alterando particularismos culturais.

Em outras palavras, as religiōes não podem permanecer impassíveis em um contexto de globalização. De fato, assistimos atualmente ao surgimento de novas formas de religião com expressōes nos níveis individual, grupal e social. Nessa direção, José Casanova identifica duas grandes mudanças no campo da religião: a revitalização das grandes tradições ou "religiôes do mundo", mas como comunidades religiosas "imaginadas", transnacionais e globalizadas, ou seja, assiste-se a uma explosão de comunidades religiosas desterritorializadas, onde a comunidade (Gemeinshaft) tem se reconstruído de muitas formas ao libertar-se das restriçōes territoriais do Estado-nação ou de algum outro tipo de comunidade étnica territorial (Casanova, 2001, pp. 427-434). A outra mudança diz respeito à "desprivatização religiosa", ou seja, a incursão da religião na esfera pública e no campo de batalha do protesto político, não só para defender seu feudo tradicional, mas também para participar das mesmas lutas no sentido de definir e assentar as fronteiras modernas entre as esferas pública e privada, entre legalidade e moralidade, entre família, sociedade civil, economia e Estado na escala global (Casanova, 1995, pp. 404-406). Mas esta dinâmica, segundo o autor, não implica a ressacralização da sociedade ou uma mudança da cultura política secular, já que tal desprivatização acontece justamente em uma "arena" pluralista que supõe, por princípio, um Estado laico-secular e que, como tal, possibilita a participação de diferentes atores na esfera pública, entre eles, os religiosos. ${ }^{11}$ Teoricamente, isto não exclui a emergência e, em alguns casos, a revitalização dos fundamentalismos, já que é também inevitável sua presença, "entrincheirados" ou numa franca "cruza- da" em face de uma agressiva realidade plural e globalizada que ameaça diluir e banalizar suas crenças, o que resulta, em última instância, em uma forma indireta de confirmar o caráter global e plural da religião.

$\mathrm{Na}$ sociedade global coexistem diversas formas sociais de religião (institucionalizada, politizada, fundamentalista, invisível, emocional etc.), contudo, nem todas possuem as mesmas condições de plausibilidade. Enquanto a religião institucionalmente organizada encontra-se em um contexto desfavorável devido ao pluralismo e seus efeitos relativistas e sincréticos, as outras, sobretudo a religião "individual-emocional", têm ali um ambiente mais conveniente (Beyer, 1999, pp. 296-297). No entanto, já que a dinâmica da globalização não opera sozinha, mas está em permanente interação e tensão com o plano "local" (em que a religiāo desempenha papel de enraizamento importantíssimo), resta a tarefa de estudar casos concretos sobre a influência religiosa nas sociedades da modernidade tardia e globalizada.

\section{Conclusão}

Grande parte das primeiras teorias sociológicas a respeito da secularização concentrou sua atenção em tentar explicar a perda da relevância social e subjetiva da religião nas sociedades modernas. $\mathrm{O}$ contexto polêmico do momento e o pressuposto do pensamento iluminista que preconizava a incompatibilidade entre o pensamento racional e a religião marcariam as reflexões sobre a secularização como teoria explicativa e preditiva do declínio da religião na modernidade. A persistência da religião e, em muitos casos, o crescente papel de protagonista adquirido na dinâmica social de nossas sociedades hipermodernas e globalizadas têm levado muitos a pensar na obsolescência das teorias sociológicas sobre a secularização.

O debate sociológico contemporâneo a esse respeito revelou que, embora muitas das primeiras teorias de secularização tenham sido concebidas com base no viés iluminista, estas teorias mostraram uma série de mudanças socioestruturais, como a diferenciação institucional e o pluralismo, que 
tornaria irreversível a descentralização e o deslocamento experimentado pela religião nos processos de modernização, inclusive nas condições atuais da modernidade radicalizada e globalizada que assiste ao ressurgimento e à revalorização da religião. Para a maioria dos autores aqui analisados, esses fatos, em vez de debilitar ou fazer retroceder as mudanças socioestruturais a um estado pré-modernidade, prevaleceram principalmente porque a dinâmica e as características do ressurgimento religioso se ergueram com base no "espírito" da modernidade radicalizada (pluralismo, preeminência do emocional, desconfiança da razão etc.). Certamente essa situação não exclui a possibilidade de que grupos ou movimentos religiosos permaneçam com uma clara atitude de retrocesso, como acontece com quase todos os fundamentalismos, embora tudo indique que eles não possam mais vislumbrar um futuro promissor.

Outro aspecto relevante do debate sociológico contemporâneo sobre a religião concerne à utilidade analítica das reflexões sobre a secularização em um contexto de modernidade globalizada para explicar a desterritorialização das identidades religiosas, a formação de comunidades transnacionais "imaginadas" e o efervescente sincretismo da grande maioria das religióes.

Sem dúvida a teoria da secularização se confrontará continuamente com investigações empíricas que lhe permitam revisar seus pressupostos, ajustar seus marcos explicativos e facilitar, desse modo, uma melhor compreensão de nossas sociedades.

\section{Notas}

1 Para uma apresentação sucinta dos antecedentes históricos e usos semânticos da noção de secularização, ver Marramao (1988).

2 A bibliografia sobre a modernidade é imensa, para uma visão geral, ver Berger e Kellner (1979), Gidens (1990), Habermas (1989, pp. 131-144), Wagner (1997).

3 Uma síntese básica sobre esta perspectiva, ver Entrena (2001).

4 Tschannen têm consciência de que, na delimitação do paradigma da secularização, excluiu autores re- levantes como Habermas, Luhmann e Stark, entre outros, os quais, trabalham o tema a partir outras vertentes teóricas.

5 Para ampliar este tema, ver Mardonnes (1991, 1998, 1999).

6 Aqui situam-se geralmente autores neoconservadores, como Daniel Bell, Peter Berger, Robert Nisbet e Michael Novak; e pós-modernos, como Gianni Vattimo, François Lyotard e Jean Baudrillard, entre outros.

7 Isto é o que fundamentalmente propõe Ulrick Beck quando distingue entre uma primeira modernidade Ilustrada e uma posterior, denominada "reflexiva" (Beck, 1996, pp. 223-265).

8 O caso latino-americano é um exemplo interessante nesse sentido, pois se trata de uma região com um profundo enraizamento religioso e onde se observa grande efervescência religiosa, mas não necessariamente o restabelecimento do poder político da igreja católica, nem a ressacralização do Estado, tampouco o incremento na filiação, se não seu declínio.

9 Alguns vêem esse tipo de "retorno" em sociedades islâmicas como Irã. Mas tais comparaçôes não se aplicam, já que a sociedade iraniana nunca chegou propriamente a ser moderna.

10 Teólogos europeus, como Graham Ward, William Cavanaugh e John Miltbank, estão incursionando com uma impressionante bagagem intelectual neste debate sobre as relações entre fé e razão em um contexto pós-secular.

11 Karel Dobbelaere, por outro lado, tem advertido em seus trabalhos como a diferenciação entre as esferas pública e privada não é algo objetivo, e sim definições sociais usadas por indivíduos e grupos, principalmente com um sentido político orientado a restringir ou alargar a influência social da religião (Dobbelaere, 1985, p. 381).

\section{BIBLIOGRAFIA}

BASTIAN, J. P. (1997), La mutación religiosa en América Latina. México, Fondo de Cultura Económica.

BECK, U. (1996), "Teoría de la modernidad reflexiva", in Josetxo Beriain (org.), Las consecuencias perversas de la modernidad, Barcelona, Anthropos, pp. 223-265.

BERGER, P. (1981), Para una teoría sociológica de la religión. Barcelona, , Kairós. 
(1993), "La secularización y el pluralismo", in , Una gloria lejana, Barcelona, Herder, pp. 39-64.

BERGER, P. \& KELLNER, H. (1979), Un mundo sin hogar: modernización y conciencia. Santander, Sal Terrae.

BERIAIN, J. (org.). (1996), Las consecuencias perversas de la modernidad. Barcelona, Anthropos. . (2005), Modernidades en disputa. Barcelona, Anthropos.

BEYER, P. (1994), Religion and globalization. Londres, Sage Publications.

. (1999), "Secularization from the perspective of globalization: a response to Dobbelaere". Sociology of Religion, 60 (3): 289-301.

CASANOVA, J. (1995), “Dimensiones públicas de la religión en las modernas sociedades occidentales". Iglesia Viva, 178-179: 395-410.

. (2001), "Religion, the new millennium, and globalization”. Sociology of Religion, 62 (4): 415-441.

. (2007), "Reconsiderar la secularización: una perspectiva comparada mundial". Revista Académica de Relaciones Internacionales, 7: $1-20$.

DOBBELAERE, K. (1985), "Secularization theories and sociological paradigms: a reformulation of the private-public dichotomy and the problem of societal integration". Sociological Analysis, 4: 377-387.

(1994), Secularización: un concepto multidimensional. México, Universidad Iberoamericana.

DURKHEIM, E. (1982), Las formas elementales de la vida religiosa. Madri, Universidad Iberoamericana.

ENTRENA, F. (2001), Modernidad y cambio social. Madri, Trotta.

GIDDENS, A. (1990), Consecuencias de la modernidad. Madri, Alianza.

HABERMAS, J. (1989), "Modernidad un proyecto incompleto”, in Vários Autores, El debate modernidad posmodernidad, Buenos Aires, Punto Sur, pp. 131-144.

. (2001), "Fe y saber". Discurso de agradecimento pronunciado por Jürgen Habermas na Pauslkirche de Frankfurt, em 14 de outubro de 2001. Disponível em <www.mercaba.org/ ARTICULOS/D/debate_Habermas_Ratzinger.htm\#Fe\%20y\%20Saber>.

. (2004), "Fundamentos morales prepolíticos del estado liberal”. Disponível em <www.almendron.com/politica/pdf/2005/reflexion/reflexion_0648.pdf>.

HERVIEU-LEGER, D. (1987), "Secularización y modernidad religiosa”. Selecciones de Teología, 26 (103), pp. 217-227.

LEGORRETA, J. J. (2003), Cambio religioso y modernidad en México. México, Universidad Iberoamericana.

LUCKMANN, T. (1973), La religión invisible: el problema de la religión en la sociedad moderna. Salamanca, Sígueme.

. (1989), "Religión y condición social de la conciencia moderna", in Vários Autores, Razón, ética y política: el conflicto de las sociedades modernas, Barcelona, Anthropos, pp. 87-108.

MARDONES, J. M. (1991), "Para un diagnóstico sociocultural de nuestro tiempo", in , Postmodernidad y neoconservadurismo, Estella, Verbo Divino, pp. 15-36.

- (1994), Para comprender las nuevas formas de la religión. Estella, Verbo Divino.

(1998), El discurso religioso de la modernidad: Habermas y la religión. Barcelona, Anthropos/UIA.

. (1999), Sintomas de un retorno: la religión en el pensamiento actual. Santander, Sal Terrae.

MARRAMAO, G. (1988), Cielo y tierra: genealogía de la secularización. Barcelona, Paidós.

MARTELLI, S. (1999). "Ni secularización ni resacralización, más bien desecularización: la teoría sociológica de la religión ante el cambio actual". Religiones y Sociedad, 7: 153-167.

MARTIN, D. (1991), "The secularization issue: prospect and retrospect". The British Journal of Sociology, 3: 465-474.

RUBIO, J. M. (1998), “'Resurgimiento religioso' versus secularización?”. Gaceta de Antropología, 14, pp. 1-19.

STARK, R. (1999), "Secularization, R.I.P.”. Sociology of Religion, 60 (3): 249-273. 
TOMLINSON, J. (2001), Globalización y cultura. México, Oxford.

TSCHANNEN, O. (1991), “The secularization paradigm: a systematization". Journal for the Scientific Study of Religion, 4: 395-415.

. (2004), "La revaloración de la secularización mediante la perspectiva comparada Europa latina-America Latina", in Jean Pierre Bastian (org.), La modernidad religiosa: Europa latina y América Latina en perspectiva comprada, México, Fondo de Cultura Económica, pp. 353-365.

VOYÉ, L. (1999), "Secularization in a context of advanced modernity". Sociology of Religion, 60 (3): 275-288.

WAGNER, P. (1997), Sociología de la modernidad. Barcelona, Herder.

WILSON, B. (1998), "The secularization thesis: criticisms and rebuttals", in Laermans et al., Secularization and social integration. Papers in honor of Karel Dobbelaere, Louvain, Leuven University Press., pp. 45-65.

WEBER, M. (2000), El politico y el cientifico. Madri, Alianza. 


\section{SECULARIZAÇÃO OU \\ RESSACRALIZAÇÃO: $O$ \\ DEBATE SOCIOLÓGICO \\ CONTEMPORÂNEO SOBRE A \\ TEORIA DA SECULARIZAÇÃO}

José de Jesús Legorreta Zepeda

Palavras-chave: Secularismo; Religião;

Modernidade; Globalização.

O que é comumente chamado de "ressurgimento" da religião não tem trazido um retorno subjetivo na ordem pré-moderna da sociedade. Esta revitalização é consequiência da sensibilidade e das tendências de uma radical e globalizante modernidade. Nesta situação, diversos sociólogos da religião têm analisado o conceito multidimensional da secularização e esquemas mecanicistas e teleológicos com que o conceito surgiu no século XIX por conta da presença de novas religiōes no contexto da modernidade global.

\section{SECULARIZATION OR \\ RESACRALIZATION? THE \\ CONTEMPORARY DEBATE OVER \\ THE SECULARIZATION OF THE SOCIOLOGICAL THEORY}

José de Jesús Legorreta Zepeda

Keywords: Secularization; Religion; Modernity; Globalization.

What is commonly called the "resurgence" of religion has not brought a subjective return in the pre-modern order of society. This revival is the result of the sensitivity and trends of a both radical and global modernity. In this situation, several sociologists of religion have examined the multidimensional concept of secularization as well as mechanistic and theological schemes with which the concept emerged in the nineteenth century due to the presence of new religions in the context of global modernity.

\section{SÉCULARISATION OU RESACRALISATION? LE DÉBAT SOCIOLOGIQUE CONTEMPORRAIN À PROPOS DE LA THÉORIE DE LA SÉCULARISATION}

José de Jesús Legorreta Zepeda

Mots-clés: Sécularisme ; Religion ; Modernité ; Mondialisation.

Ce qui est couramment appelé de "réapparition" de la religion ne nous apporte pas un retour subjectif à l'ordre pré-moderne de la société. Cette revitalisation est la conséquence de la sensibilité et des tendances d'une modernité radicale et globalisante. C'est ainsi que plusieurs sociologues de la religion ont analysé le concept multidimensionnel de la sécularisation et des schémas mécanicistes et téléologiques à partir desquels le concept a surgi au XIXe siècle, suite à la présence de nouvelles religions dans le contexte de la modernité mondiale. 